\title{
Plant Polyisoprenoids and Control of Cholesterol Level
}

\author{
Alexander V. Pronin • Leonid L. Danilov • \\ Alexander N. Narovlyansky • Alexander V. Sanin
}

Received: 4 January 2013/Accepted: 21 August 2013/Published online: 31 August 2013

(C) The Author(s) 2013. This article is published with open access at Springerlink.com

\begin{abstract}
The ability of plant polyisoprenoids (polyprenols and polyprenyl phosphates) to diminish the levels of serum cholesterol affecting its biosynthetic pathway are highlighted here. Possible mechanism of such process is discussed. It is also noted that polyisoprenoids can prevent toxic injuries of the liver and restore disturbed hepatic functions. The possibility of polyprenyl phosphates to reveal at the same time anti-inflammatory action suppressing lipoxygenase activity and lowering the levels of proinflammatory cytokines will be illustrated. Attention will be focused on the potential usefulness of plant polyisoprenoids in the course of prevention and treatment of hypercholesterolemia. High efficiency for combined use of polyprenyl phosphate and $\beta$-sitosterol, which leads to substantial enhancement of the ability to overcome hypercholesterolemia versus the individual constituents will be demonstrated.
\end{abstract}

Keywords Polyisoprenoids $\cdot \beta$-Sitosterol - Sitopren · Cholesterol $\cdot$ Atherosclerosis

$\begin{array}{ll}\text { Abbreviations } \\ \text { ABCG7/9 } & \text { ATP-binding cassette (ABC) transporters } \\ \text { ALT } & \text { Alanine transaminase } \\ \text { ATP } & \text { Adenosine } 5 \text { '-triphosphate } \\ \text { BAFS } & \text { Biologically active food supplement } \\ \text { DolOH } & \text { Dolichols }\end{array}$

A. V. Pronin $(\bowtie)$ - A. N. Narovlyansky · A. V. Sanin N. F. Gamaleya Research Institute of Epidemiology and Microbiology, Moscow, Russia e-mail: proninalexander@yandex.ru

L. L. Danilov

N. D. Zelinsky Institute of Organic Chemistry, Russian Academy of Sciences, Moscow, Russia

$\begin{array}{ll}\text { FarPP } & \text { Farnesyl diphosphate } \\ \text { GBP } & \text { Polyprenols isolated from Ginkgo biloba L. } \\ & \text { leaves } \\ \text { GerGerPP } & \text { Geranylgeranyl diphosphate } \\ \text { GerPP } & \text { Geranyl diphosphate } \\ \text { GTP } & \text { Guanosine-5'-triphosphate } \\ \text { HMG-CoA } & \text { 3-Hydroxy-3-methylglutaryl-coenzyme A } \\ \text { IFN } & \text { Interferon } \\ \text { IL } & \text { Interleukin } \\ \text { LDL } & \text { Low density lipoprotein } \\ \text { NADPH } & \text { Oxidase, nicotinamide adenine dinucleotide } \\ & \text { phosphate-oxidase } \\ \text { NFKB } & \text { Nuclear factor kappa B } \\ \text { PI } & \text { Polyisoprenoids } \\ \text { PI-OH } & \text { Polyisoprenoid alcohols } \\ \text { PreOH } & \text { Polyprenols } \\ \text { SREBP2 } & \text { Sterol regulatory element-binding protein } 2 \\ \text { STAT1/2 } & \text { Signal transducer and activator } \\ & \text { transcription } 1 / 2 \\ \text { TC } & \text { Total cholesterol } \\ \text { TG } & \text { Triglycerides } \\ \text { THP-1 } & \text { Human acute monocytic leukemia cells } \\ \text { TLR } & \text { Toll-like receptor } \\ \text { TNF } & \text { Tumor necrosis factor } \\ \text { TP } & \text { Polyprenols isolated from Taxus chinensis } \\ & \text { var. mairei needles } \\ & \end{array}$

\section{Introduction}

Isoprenoids represents a large and diverse class of naturally occurring organic substances derived from five-carbon isoprene units assembled and modified in diverse ways. Polyisoprenoid alcohols (PI-OH) include polyprenols (PreOH) and dolichols (2,3-dihydropolyprenols, DolOH). 


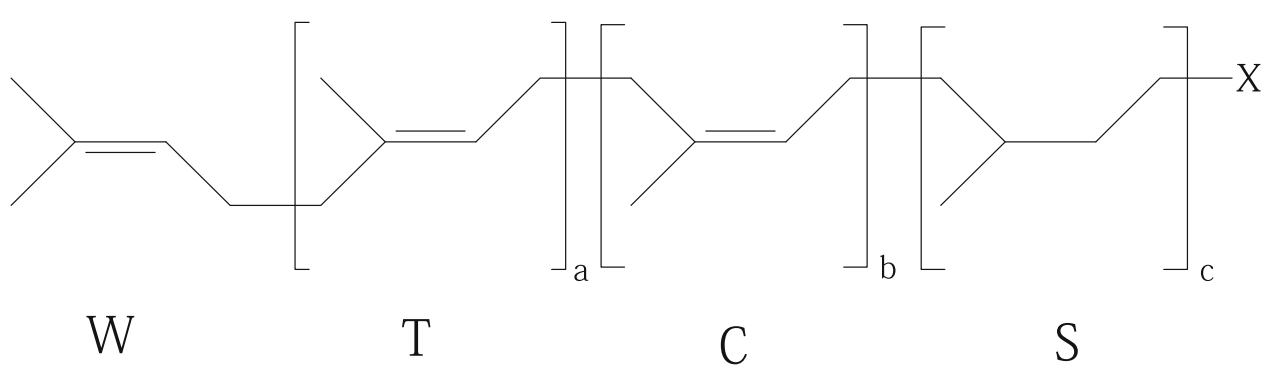

Fig. 1 Common formula for polyisoprenoid alcohols and their phosphates. W, $\omega$-isoprene unit; T, trans-isoprene unit; $\mathrm{C}$, cisisoprene unit; S, 2,3-dihydroisoprene unit; $\mathrm{a}, \mathrm{b}$, and $\mathrm{c}$ means a number of $\mathrm{T}, \mathrm{C}$, and $\mathrm{S}$-isoprene units, respectively; $\mathrm{S}=0$ (for polyprenols) or

PI-OH consists of at least four isoprene units linked headto-tail (Fig. 1). Molecule of PreOH assembles from $\omega$ isoprene unit, two or three trans-isoprene units, specified number of cis-isoprene units, and $\alpha$-isoprene unit, which has cis-configuration and hydroxygroup at $\mathrm{C}-1$ carbon atom; DolOH contain saturated $\alpha$-unit (IUPAC-IUB Joint Commission on Biochemical Nomenclature 1987). The hydrogenation is catalyzed by steroid $5 \alpha$-reductase SRD5A3 (Cantagrel et al. 2010). Long-chain linear isoprenoid alcohols are ubiquitous and essential components of cellular membranes of all living organisms (Hartley and Imperiali 2012; Jones et al. 2009; Surmacz and Swiezewska 2011; Swiezewska and Danikiewicz 2005). Polyprenols are isolated mostly from bacteria and green parts of plants, DolOH are typical for fungi and animals. Free PI-OH and their fatty acid esters serve as structural components of cellular membranes modulating their physico-chemical properties such as fluidity and permeability and inducing the formation of non-bilayer zones (hexagonal $\mathrm{H}_{\mathrm{II}}$ phase) (Chojnacki and Dallner 1988; Hartley and Imperiali 2012; Wang et al. 2008). They are also believed to be the reserve pool of polyisoprenoids for biosynthesis of polyprenyl phosphates in case of need. Phosphates of these PI-OH besides analogous membranotropic behavior serve as the specific membrane-bound intermediary carriers for glycosyl and oligosaccharyl residues in glycan biosynthetic pathways responsible for the production of cellular components such as N-linked glycoproteins or bacterial peptidoglycan (Hartley and Imperiali 2012; Jones et al. 2009; Larkin and Imperiali 2011; Schenk et al. 2001). These functions of PI are of extraordinary significance because genetic disturbances of biosynthetic pathways in which PI and their derivatives participate lead to grave (sometimes fatal) consequences known as congenital disorders (Cantagrel and Lefeber 2011; Cantagrel et al. 2010; Goreta et al. 2012; Grundahl et al. 2012; Kranz et al. 2007). Similar abnormalities are observed at fetal alcohol syndrome particularly as a result of suppression of biosynthesis of dolichol (dolichyl
1 (for 2,3-dihydropolyprenols); $\mathrm{X}, \mathrm{OH}$ for polyprenols and dihydropolyprenols (dolichols); and $\mathrm{X}, \mathrm{OPO}_{3}{ }^{2-}$ for polyprenyl phosphates and 2,3-dihydropolyprenyl (dolichyl) phosphates

phosphate) from mevalonate by ethyl alcohol (Binghorst et al. 2012).

In animals, PI are synthesized via mevalonate pathway (for recent reviews see, e.g., Buhaescu and Izzedine 2007; Rauthan and Pilon 2011). The mevalonate pathway converts acetyl-CoA to several metabolically important molecules including farnesyl diphosphate (FarPP) and geranylgeranyl diphosphate (GerGerPP) as well as physiologically important end-products. FarPP and GerGerPP are parent compounds for prenylation of proteins particularly G-proteins and earlier viral proteins (Clase et al. 2003; Einav and Glenn 2003; Kapadia and Chisari 2005), and also for biosynthesis of isoprenoid chain of coenzyme $\mathrm{Q}_{10}$ (an antioxidant also important in the electron transport chain in mitochondria), $\mathrm{PI}-\mathrm{OH}$ and their phosphates (important for protein glycosylation). FarPP is a substrate for enzymatic synthesis of cholesterol (important for cell membrane structure and precursor for bile acid and steroid hormones). Thus, cholesterol and polyisoprenoids are biogenetically related compounds (Skorupinska-Tudek et al. 2008). Many enzymes catalyze the multistep pathway, and several therapeutic inhibitors exist that target some of these enzymes, including statins typically prescribed to lower blood cholesterol level. But these therapeutics have several undesired effects. Statins inhibit 3-hydroxy-3-methylglutaryl-coenzyme A (HMG-CoA) reductase, the rate-limiting enzyme in cholesterol biosynthesis, which converts HMG-CoA to mevalonate. Statins lower plasma low density lipoprotein (LDL) cholesterol by causing intracellular cholesterol depletion and upregulating the expression of LDL receptors. Apart from cholesterol, mevalonate is also the substrate for the synthesis of nonsteroid isoprenoids including FarPP, GerGerPP (both attached to small GTPbinding proteins by protein prenyltransferases), coenzyme $\mathrm{Q}_{10}$, dolichol, isopentenyladenosine, and so on. Depletion of these isoprenoids results in so-called "pleiotropic" effects of statins, which are independent of cholesterol lowering. Although statins are generally well-tolerated, adverse effects may occur in some patients. These effects 
Fig. 2 Structural formula of sodium polyprenyl phosphate obtained by phosphorylation of polyprenols from fir (Abies sibirica) or pine (Pinus sylvestris) needles
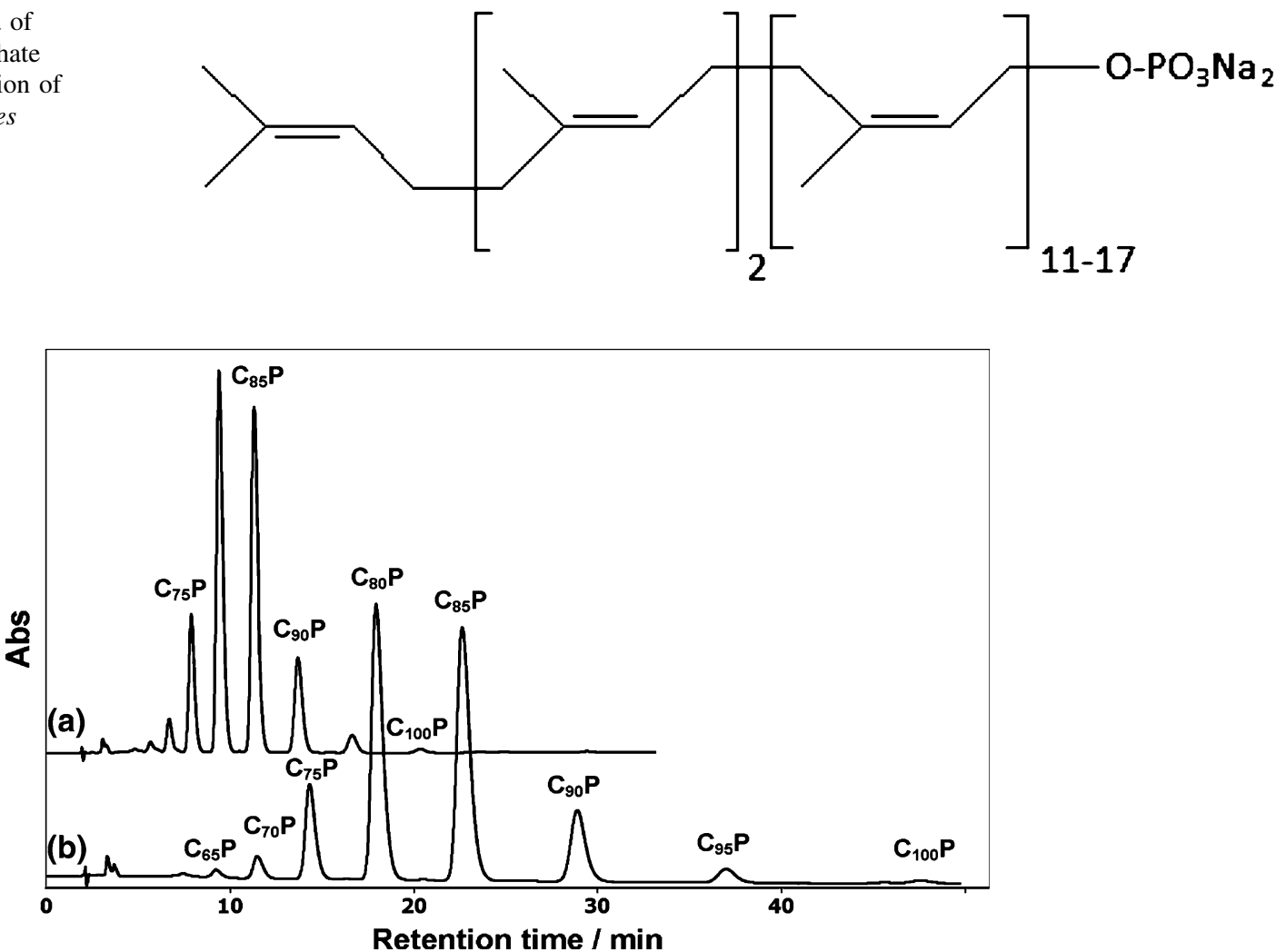

Fig. 3 Separation of polyprenyl phosphate oligomerhomologues by reversed-phase ion-pair high-performance liquid chromatography. Typical chromatograms of phosphorylated polyprenols $\left(\mathrm{C}_{\mathrm{i}} \mathrm{P}\right)$ from fir needles using a reversed-phase Kromasil C18-column $250 \times 4.0 \mathrm{~mm}$

result from impaired protein prenylation, deficiency of coenzyme $\mathrm{Q}_{10}$ involved in mitochondrial electron transport and antioxidant protection, abnormal protein glycosylation due to dolichol shortage (Beltowski et al. 2009; Rauthan and Pilon 2011).

This review is devoted mainly to one of the member of polyisoprenoids-sodium polyprenyl phosphate, which is produced via phosphorylation of PreOH from fir (Abies sibirica) or pine (Pinus sylvestris) needles. The structure of this substance can be represented by formula (see Fig. 2). Polyprenyl phosphates possess a wide spectrum of physiological effects and seem to be perspective pharmaceutical preparations of a new generation (Danilov et al. 1999, 2003). The first commercial pharmaceutical preparation PHOSPRENYL was developed in Russian Federation and since 1994 has been widely used in the veterinary practice preferably as efficient antiviral drug (Danilov et al. 1996). At the present time, clinical trials of FORTEPREN (the analog of PHOSPRENYL for human) are in progress. The main active ingredient of these preparations is sodium polyprenyl phosphate, which represents the family of oligomerhomologues containing mainly 14-20 isoprene units in the hydrocarbyl radical (Kozlov and Danilov 2012) (Fig. 3). inner diameter, $5 \mu \mathrm{m}$ (Eka Chemicals, Sweden) and the mobile phase with the addition $0.020 \mathrm{M}$ tetrabutylammonium dihydrogen phosphate. Conditions: $(a)$ ethanol/hexane $(87: 13 \mathrm{v} / \mathrm{v}) ;(b)$ ethanol/hexane (90:10 v/v); flow rate: $0.85 \mathrm{ml} / \mathrm{min}$ (from Kozlov and Danilov 2012)

The reason to use polyprenyl phosphates first and foremost as antiviral drug was based upon the data about their ability to exert antiviral action at wide range of serious viral infections such as influenza, herpes simplex, yellow fever, hepatitis, rabies, canine distemper, tick-borne encephalitis, and so on (Danilov et al. 1999, 2003; Ozherelkov et al. 2000; Vasil'ev et al. 2008). The preparations are shown to provoke the production of defected virions, for example, from tick-borne encephalitis virus (strain Soph'in), which was titrated on pig kidney epithelial cell line (SPEV). Electron microscopy morphological study (Fig. 4; negative staining with phosphowolframic acid) revealed that after incubation with polyprenyl phosphate, the majority of virions (65-75\%) had distended or defective envelope. Small viral particles having $20 \mathrm{~nm}$ diameter (30-40 nm diameter is normal) were sometimes (5-7\%) found (probably virions lacking envelope). Such virions were not found in control probes. Besides that considerable decrease (relative to control) in number of viral particles was detected in experimental probes. It seems that polyprenyl phosphates disturb the process of viral particle assembly and withdrawal them from the infected cells. But PI possess simultaneously a lot of other 


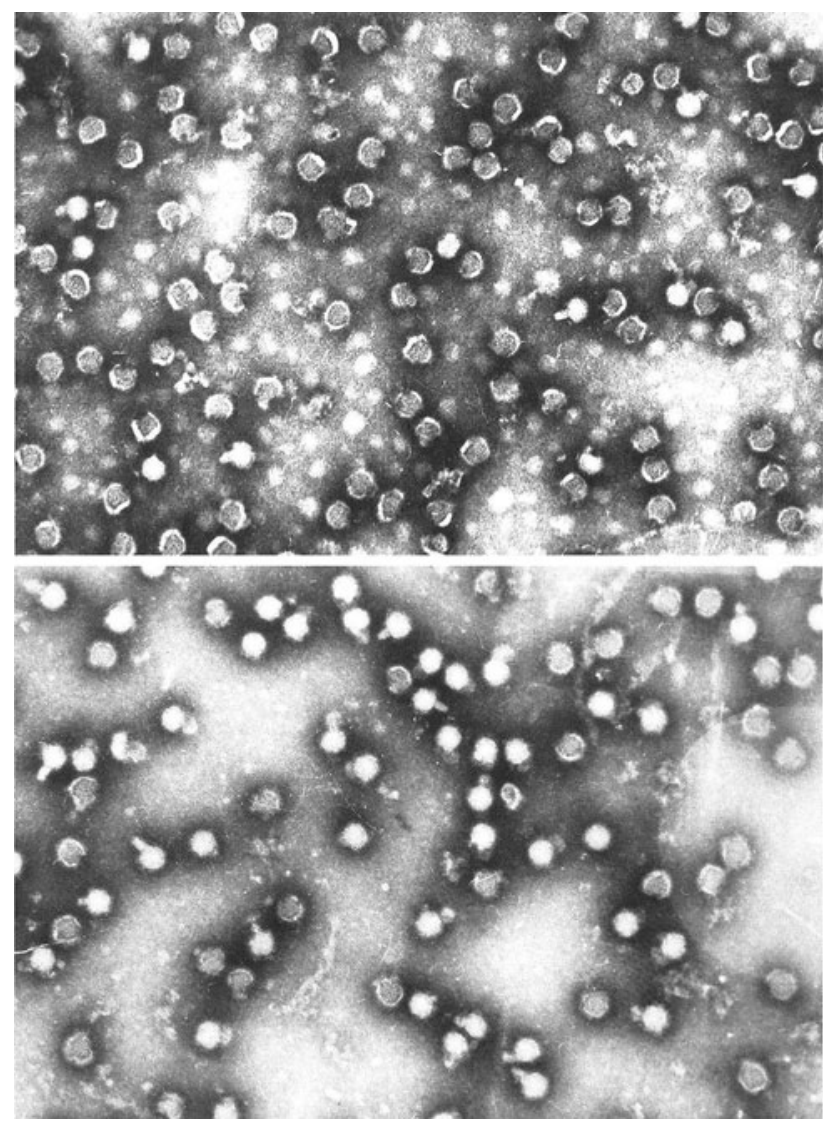

Fig. 4 Formation of defected viral particles under influence of sodium polyprenyl phosphate. Top photograph tick-borne encephalitis virions after 2-h incubation with $200 \mu \mathrm{g} / \mathrm{ml}$ of disodium polyprenyl phosphate $(50 \mu \mathrm{l} / \mathrm{ml}$ of $0.4 \% \mathrm{w} / \mathrm{v}$ solution of the phosphate in complex aqueous solvent containing $3 \% \mathrm{v} / \mathrm{v}$ of glycerol, $3 \% \mathrm{v} / \mathrm{v}$ of ethanol and $0.2 \% \mathrm{v} / \mathrm{v}$ of Tween- 80 in water for injection). Bottom photograph tick-borne encephalitis virions after 2-h incubation with placebo (equal volume of the solvent without the polyprenyl phosphate)

physiological properties, which are valuable from medicinal point of view.

\section{Antihypercholesterolemic and Antihyperlipidemic Action of Polyisoprenoids}

It was shown previously (Yamatsu et al. 1986) that in streptozotocin-treated rats, the levels of total cholesterol (TC) and triglycerides (TG) in blood are reliably raised. Injection of dolichol or dolichyl phosphate $(15 \mathrm{mg} / \mathrm{kg} / \mathrm{day})$ to experimental animals led to substantial lowering of TC and TG levels (TC by $50 \%$ and TG by $75 \%$ ).

Recently, it was demonstrated that $\mathrm{PreOH}$ are active ingredients of some officinal plants, which are able to ameliorate lipid metabolism, for example, ivy gourd (Coccinia grandis) (Tamilselvan et al. 2011). Ivy gourd is a tropical plant used in herbal medicine. Available in supplement form, extracts of the ivy gourd's roots, fruit, and leaves are known to offer a range of health benefits. Administration of $\mathrm{PreOH}$ isolated from $C$. grandis decreased serum TC by $25 \%$ and TG by $42 \%$ in high-fat diet-fed dyslipidemic hamsters at a dose of $50 \mathrm{mg} / \mathrm{kg} / \mathrm{day}$. The results were comparable to the action of standard drug fenofibrate at a dose of $108 \mathrm{mg} / \mathrm{kg}$ (Singh et al. 2007). Based on these investigations, it can be concluded that PreOH possess marked antidyslipidemic activity.

So, it was revealed that PI display both antiviral properties and the ability to lower the level of cholesterol and triglycerides in blood. Both these effects are seemingly "the links of the same chain". The confirmation of this supposition is particularly the data obtained by Kuritz (2009). It was demonstrated that addition of polyprenyl phosphates stimulated production of tumor necrosis factor (TNF) in THP-1 cell culture after $3.5 \mathrm{~h}$ of such treatment, and antibodies against Toll-like receptor (TLR) 2 or TLR4 or their mixture suppressed this stimulation, which means that polyprenyl phosphates were able to interact with TLRs. The increase in intracellular concentration of calcium ions was registered just a few seconds after the addition of polyprenyl phosphate.

Calcium-mediated signaling is an essential condition for cell stimulation. The next stage of the stimulation is an activation of transcriptional factor NFKB. Figure $5 \mathrm{dem}-$ onstrates that in 1-3 days after PreP injection in mice expression of $\mathrm{NF \kappa B}$ in splenocytes is intensified. One of the final products of these activation are interferons (IFNs).

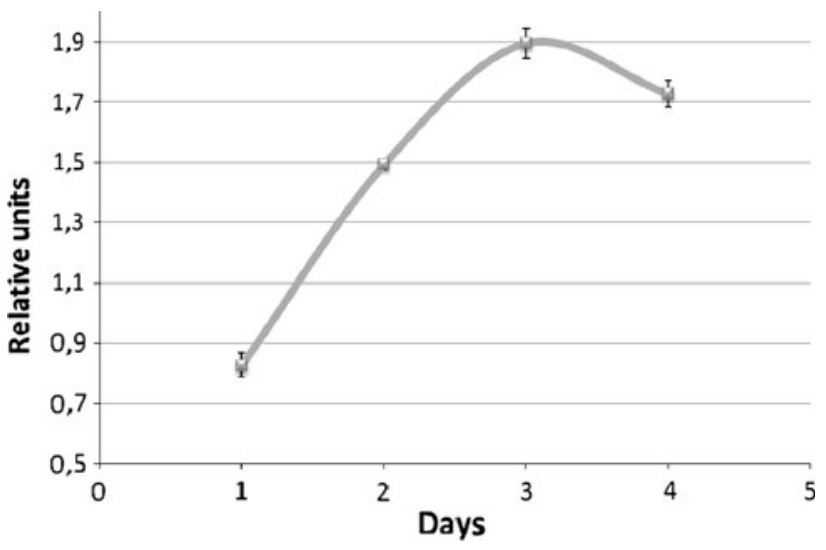

Fig. 5 Expression of NFKB by mice splenocytes stimulated with sodium polyprenyl phosphate (RT-PCR). BALB/c mice ( $\geq 10$ animals in each group) were used. The experimental mice were intramuscularly injected with $20 \mu \mathrm{g}$ of disodium polyprenyl phosphate $(5 \mu \mathrm{l}$ of $0.4 \% \mathrm{w} / \mathrm{v}$ solution of the phosphate in complex aqueous solvent containing $3 \% \mathrm{v} / \mathrm{v}$ of glycerol, $3 \% \mathrm{v} / \mathrm{v}$ of ethanol and $0.2 \% \mathrm{v} / \mathrm{v}$ of Tween-80 in water for injection diluted to $0.2 \mathrm{ml}$ with the water) three times every $2 \mathrm{~h}$, the control group animals-with placebo (equal volume of the solvent without the active ingredient). Shown are mean values $\pm \mathrm{SD} ; p<0.05$ 
It was demonstrated that PreP induced the production of type I and II IFN both in vitro and in vivo. Adding polyprenyl phosphate in a dose of $200 \mu \mathrm{g} / \mathrm{ml}$ (in the form of $0.4 \% \mathrm{w} / \mathrm{v}$ solution of the phosphate in complex aqueous solvent containing $3 \% \mathrm{v} / \mathrm{v}$ of glycerol, $3 \% \mathrm{v} / \mathrm{v}$ of ethanol, and $2 \% \mathrm{v} / \mathrm{v}$ of Tween-80 in water for injection) to the culture of intact murine spleen cells or pig kidney epithelium cells resulted in increasing of IFN titer in the culture liquid to 2.2-3.5 times in comparison with the control cell culture to which the complex solvent without polyprenyl phosphate was added. Infecting the cells with thick-borne encephalitis viruses without adding polyprenyl phosphate gave rise to similar stimulation. Much higher IFN titer increasing (about fourfold) were detected in the cultures treated both polyprenyl phosphate and tick-borne encephalitis viruses. Similar phenomenon was revealed upon analogous adding polyprenyl phosphate to the culture of intact Taurus- 1 cells or to the cells infected with infectious bovine rhinotracheitis viruses. So, pronounced interferonogenic activity of polyprenyl phosphate per se and its potentiation of interferonogenic activity of some viruses in vitro were demonstrated (Ozherelkov et al. 2007). Intramuscular injection of $20 \mu \mathrm{g}$ of disodium polyprenyl phosphate $(5 \mu \mathrm{l}$ of $0.4 \%$ solution of the phosphate in the same complex aqueous solvent diluted to $0.2 \mathrm{ml}$ with water for injection) to $\mathrm{BALB} / \mathrm{c}$ mice (intact or infected intraperitoneally with tick-borne encephalitis viruses) similarly increased the level of IFN in the blood serum of the animals (Pronin et al. 2012).

As mentioned above, the signal generated after interaction of PreP with TLR2/4 leads to activation of NFKB providing synthesis of type I IFNs. The latter after interaction with receptors IFN- $\gamma$ receptor 1 induces consecutive activation of Janus kinase 1, tyrosine kinase 2, and STAT1/ 2 , then activation of IFN-stimulated genes and suppression of SREBP2 transcriptional factor (Blanc et al. 2011). This factor (sterol regulatory element-binding protein) is the main regulator of mevalonate pathway producing early precursors of isoprenoids, namely GerPP, FarPP, and GerGerPP. These precursors are also indispensable for prenylation of viral proteins because suppression of their biosynthesis leads to abnormal assembling of viral capsid and forming defective avirulent virions (Clase et al. 2003; Einav and Glenn 2003; Kapadia and Chisari 2005). FarPP is converted into squalene from which cholesterol is produced. FarPP is also shown to be the precursor for de novogenerated polyisoprenoids, which supplement pool of Do$1 \mathrm{OH}$ and their phosphates. SREBP2 provides transcription of practically all key enzymes participating in biosynthesis of cholesterol, such as HMG-CoA synthase, HMG-CoA reductase, FarPP synthase, squalene synthase, and also LDL receptor (Ishimoto et al. 2010; Marquart et al. 2010; Sato 2010). Therefore, suppression of this transcriptional factor activity must considerably inhibits biosynthesis of cholesterol as well as endogenous polyisoprenoid production. But in the last case, possible depletion of the pool could be compensated by means of exogenous polyprenyl phosphate administration.

So, polyprenyl phosphates and statins possess diverse mode of action and do not have common features although formally the therapeutic effect (inhibiting cholesterol biosynthesis) of both of them is the same.

\section{Anti-inflammatory Activity of Polyprenyl Phosphates}

One of the valuable physiological properties of polyprenyl phosphates bearing a relation to atherosclerosis is their anti-inflammatory action. Addition of polyprenyl phosphate to cell culture caused dose-depended decrease of 5and 15-lipoxygenase activity (Sanin et al. 2011). 5-Lipoxygenase catalyses particularly production of leukotriene $\mathrm{B}_{4}$ from arachidonic acid. The leukotriene via interaction with their receptor activate presqualene diphosphate phosphatase, which catalyses conversion of presqualene diphosphate into presqualene monophosphate. Presqualene diphosphate is a potent and direct inhibitor of phospholipase D and phosphatidylinositol-3 kinase whereas presqualene monophosphate is considerably weaker one. Phospholipase D catalyses conversion of membrane phosphatidylcholine into phosphatidic acid and thus regulates such cell functions as morphologic change, degranulation, and $\mathrm{O}_{2}{ }^{-}$production. Phosphatidylinositol-3 kinase immediately activates NADPH oxidase-the main inducer of oxidative burst and associated manifestations of inflammatory process (Bonnans and Levy 2007). So, blocking lipoxygenase with polyprenyl phosphate inhibits synthesis of leukotriene $\mathrm{B}_{4}$ and following activation of presqualene diphosphate phosphatase. As a result, the active centers of phospholipase D and phosphatidylinositol-3 kinase can remain blocked with presqualene diphosphate, the catalytic activities of the enzymes can remain weak and thereby inflammation can be diminished.

\section{Hepatoprotective Properties of Polyisoprenoids}

One more substantial mode of polyisoprenoids action which has to do with control of cholesterol level is their ability to accelerate regeneration of liver tissue as well as to prevent, normalize and restore hepatic functions. It has been demonstrated (Yamatsu et al. 1986) that regeneration rate of liver in rats with partial hepatectomia was significantly increased by $20 \%$ after injection $30 \mathrm{mg} / \mathrm{kg} /$ day of dolichol or by $10 \%$ after injection $15 \mathrm{mg} / \mathrm{kg} /$ day of dolichyl phosphate. 
Along with dolichol and dolichyl phosphate, plant $\mathrm{PreOH}$ and polyprenyl phosphates manifest strongly pronounced complex influence on liver functions. These polyunsaturated substances are biogenetically congeneric to liposoluble vitamins $\mathrm{A}$ and $\mathrm{E}$, ubiquinones, and coenzyme $\mathrm{Q}_{10}$. They are postulated to possess an antioxidant, antistress, and membranoprotective activities (Bergamini et al. 2004).

The hepatoprotective effects of PreOH from Ginkgo biloba L. leaves (GBP) were evaluated against carbon tetrachloride-induced hepatic damage in Sprague-Dawley rats. The effects of GBP were comparable and not significantly different from those of the standard drug Essentiale. The results indicate that GBP could be explored as a potentially promising additive for liver diseases (Yang et al. 2011).

It was demonstrated that taxus polyprenols (TP isolated from the needles of Taxus chinensis var. mairei) successfully attenuated liver injury induced by $\mathrm{CCl}_{4}$ in rats. It was shown by histopathological sections of livers and improved liver function as indicated by lowering alanine transaminase (ALT), aspartate transaminase (AST), and alkaline phosphatase levels, increased albumin levels in serum of the animals and substantial improving other hepatic characteristics. TP also remarkably decreases in malondialdehyde content. These results suggest that the protective effects of TP in chronic $\mathrm{CCl}_{4}$-induced liver fibrosis might be related with the reduction of oxidative damage, the inhibition of hepatic stellate cells activation, the down-regulation of profibrogenic stimuli, and the protection of hepatocytes. The activity of TP (similar to GBP) was comparable with such of Essentiale as standard drug (Yu et al. 2012).

It should be mentioned that therapeutical effects were observed after administration of $48-300 \mathrm{mg} / \mathrm{kg} /$ day of the PreOH.

The first commercial pharmaceutical preparation Ropren ( $25 \%$ solution of coniferous $\mathrm{PreOH}$ in vegetable oil) was developed in Russia. Recommended doses of Ropren are $72 \mathrm{mg} /$ day for hepatoprotection and $144 \mathrm{mg} /$ day for treatment of alcoholic cirrhosis in men. In the last case, the decrease of TC (by $20 \%$ ), ALT, and AST levels was observed (Soultanov et al. 2010). In a model of dichloroethane-induced toxic hepatitis in rat Ropren at a dose $20 \mathrm{mg} / \mathrm{kg} /$ day decreased TC (by $10 \%$ ), ALT, and AST levels similar to Essentiale; regeneration rate of liver in rats with partial hepatectomia was significantly increased by $10 \%$ after injection of $40 \mathrm{mg} / \mathrm{kg} / \mathrm{day}$ of Ropren (Roschin and Soultanov 2003).

We have demonstrated high hepatoprotective action of sodium polyprenyl or dolichyl phosphate in the model of acute toxic hepatitis in mice. Doses 2-200 $\mu \mathrm{g} /$ mouse $(0.1-10 \mathrm{mg} / \mathrm{kg})$ of these substances were used for the assays. Single inoculation of the phosphates in mice $1 \mathrm{~h}$

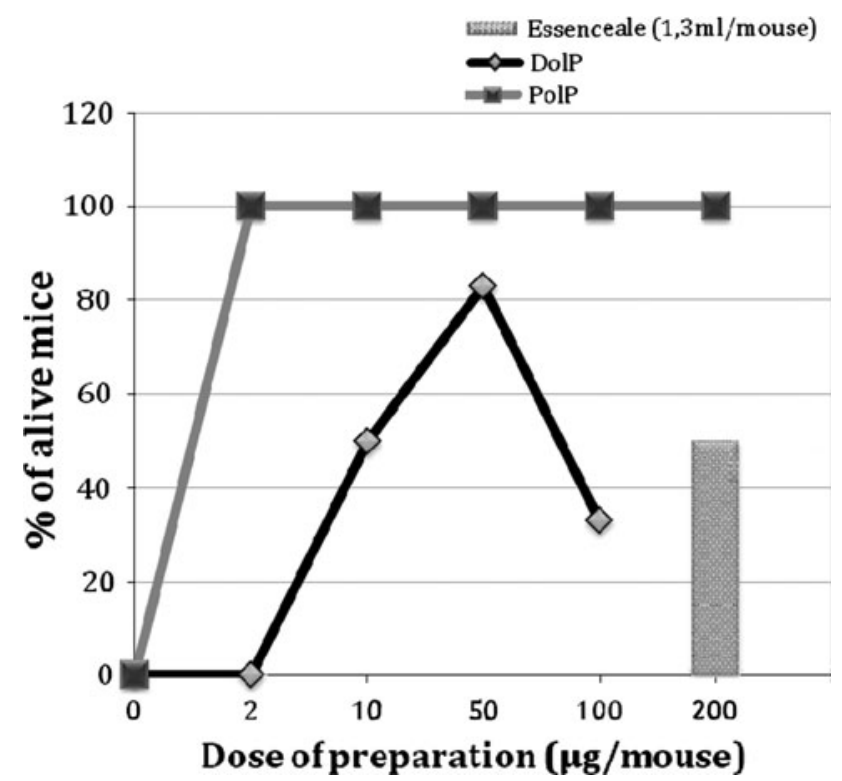

Fig. 6 Hepatoprotective effect of sodium polyprenyl or dolichyl phosphate. The preparations were injected intraperitoneally in mice at indicated doses and $1 \mathrm{~h}$ later $0.1 \mathrm{ml}$ of $\mathrm{CCl}_{4}$ was injected by the same way. The survival of the animals within 4 days was assayed, 10 mice in each group were used. As a reference preparation Essentiale $\mathrm{N}$ (Sanofi Aventis, $1.3 \mathrm{ml} / \mathrm{mouse}$ ) was utilized

before injection of $\mathrm{CCl}_{4}$ prevented the fatal outcome much more efficiently than Essentiale (Fig. 6). Dolichyl phosphate at a dose of $50 \mu \mathrm{g} / \mathrm{mouse}(2.5 \mathrm{mg} / \mathrm{kg})$ prevented the mortality of animals by $85 \%$ and polyprenyl phosphate completely prevented the mortality while efficiency of Essentiale was only $50 \%$. It seems therefore that phosphorylated plant polyprenols are substantially more potent hepatoprotectors than $\mathrm{PreOH}$ themselves.

\section{Polyisoprenods as Natural Potential Enhancers and Competitors for Up-to-Date Used Chemotherapeutic Drugs for Prevention and Treatment of Hypercholesterolemia}

Summing up the above-mentioned information concerning both biochemical and therapeutical properties of polyisoprenoids, we conclude that these compounds are able to suppress biosynthesis of cholesterol and possess antiinflammatory and hepatoprotective properties simultaneously. They are non-toxic substances and have practically no side effects (Danilov et al. 1996). Thus, they seem to be well candidates for a new perspective group of preparations for control of blood cholesterol level.

But it is quite evident that such regulation is very delicate and balanced. A suppression of synthesis of cholesterol leads to compensatory increase of its absorption from intestine with NPC1L1 protein (Niemann-Pick C1- 
like protein 1). In parallel, the activity of ATP-binding cassette transporters (ABCG7/9), which remove synthesized cholesterol from the cells (Tremblay et al. 2011) is blocked. Therefore, in parallel with statins (up-to-date main therapeutic preparations for lowering blood cholesterol level via inhibition of HMG-CoA reductase) ezetimibe (one of cholesterol absorption inhibitors) is frequently used (Sasaki et al. 2011).

The major drawback of using existent anti-cholesterol drugs is related to their side effects. So, development of alternative products which efficiently lower blood cholesterol level and do not inflict injury to organism is very actual task. Plants are the renewable available source of the compounds, which may be applicable for resolving of this problem.

\section{Phytosterols Application for Lowering Cholesterol Level}

As was mentioned above, plant $\mathrm{PreOH}$ and polyprenyl phosphates would be potential enhancers (or even competitors) for up-to-date used chemotherapeutic preparations for prevention and treatment of hyperlipidemia. These polyisoprenoids act via suppression of biosynthesis of cholesterol and lowering of cholesterol and triglyceride levels in blood owing to hepatic function normalization, and polyprenyl phosphates seems to be more efficient ones at least as hepatoprotectors.

The second group of natural compounds which is useful for blood cholesterol lowering are plant sterols (phytosterols). They were found to be an attractive alternative to synthetic inhibitors of cholesterol absorption from intestine, and $\beta$-sitosterol is most effective one among them (Fernandez and Vega-Lopez 2005). These compounds are now used as food additives and biologically active nutritional supplements. Phytosterols are sterols that are synthesized only in plants and that are structurally similar to cholesterol but with the inclusion of an extra hydrophobic fragment (ethyl radical) at the $\mathrm{C} 24$ position. Phytosterols and their esters reduce cholesterol level in the blood in spite of the fact that they are poorly absorbed in intestine. The mechanism by which phytosterols/phytosterol esters interfere with cholesterol absorption is not completely clear, but based on the present understanding, three distinct features have been recognized: (1) physico-chemical effects (e.g., competitive solubilization and co-crystallization); (2) effects at the absorption site (e.g., hydrolysis by lipases and esterases); (3) effects on intracellular trafficking of sterols (Rozner and Garti 2006). Due to poor solubilization of phytosterols in oil and water, they as a rule were used at high doses to achieve a reduction in cholesterol level. The available evidence prove that consumption of about
$1.6-2.0 \mathrm{~g} / \mathrm{day}$ of the compounds preferably dissolved in a fat-rich food matrix is effective in lowering LDL cholesterol levels by 8-10\% (Marangoni and Poli 2010). Phytosterols undoubtedly would be very useful for decrease of cholesterol levels, if their ability to suppress cholesterol absorption could appear at substantially smaller doses achieved by increasing of their bioavailability.

\section{Combined Use of Polyprenyl Phosphates and $\beta$-Sitosterol}

Recently, the information about combined use of statins as suppressors of cholesterol biosynthesis and phytosterols as inhibitors of cholesterol absorption from intestine was published, proving increased efficiency for treatment of a hypercholesterolemia (Gupta et al. 2011). It seemed to be only logical to try exchanging statins in this combination by polyisoprenoids in order to eliminate side effects without loss of the efficiency of lowering blood cholesterol level.

That was the reason why original biologically active food supplement (BAFS) containing polyprenyl phosphates and $\beta$-sitosterol, and method for their preparation was developed in Russia (Narovlyansky et al. 2011). The BAFS Sitopren contains $1 \mathrm{mg}$ of sodium polyprenyl phosphate and $6.2 \mathrm{mg} \beta$-sitosterol as the active ingredients in a unit dose (130 mg tablet).

In poloxamer 407-induced model of dyslipidemia (Johnston 2004) in mice, intragastric administration of $50 \mathrm{mg}$ /day of Sitopren $(0.4 \mathrm{mg} /$ day of sodium polyprenyl phosphate, $2.4 \mathrm{mg} /$ day of $\beta$-sitosterol) significantly decreased the level of serum cholesterol by $12 \%$. In addition, this BAFS lowered the level of triglycerides by $25 \%$. These effects were comparable with the action of $0.8 \mathrm{mg} /$ day atorvastatin (Fig. 7). The obtained data unambiguously confirm the antiatherogenic activity of Sitopren.

Peroral administration of $260 \mathrm{mg} /$ day of Sitopren ( $2 \mathrm{mg} /$ day of sodium polyprenyl phosphate, $12.4 \mathrm{mg} /$ day of $\beta$-sitosterol) during 12 weeks diminished TC and LDL levels by $9 \%$ and $12 \%$ correspondingly in a group of volunteers (Narovlyansky et al. 2011). Intake of this BAFS at the same dose and the time interval resulted in significant lowering of TC, TG and LDL levels by $11.4 \%$, $10.9 \%$, and $0.6 \%$, correspondingly, in patients with hypercholesterolemia. The levels of proinflammatory cytokines interleukin (IL)-1, IL-6 and TNF diminished simultaneously by $18.8 \%, 16.2 \%$, and $23.8 \%$. Index of atherogenicity decreased by $9.7 \%$. Negative side effects were not revealed (Nebieridze and Chernova 2012).

The results of the assays given above demonstrate high efficiency and safety of Sitopren. This BAFS markedly improves the content of lipids in blood, while significantly decreasing the levels of proinflammatory cytokines, which 


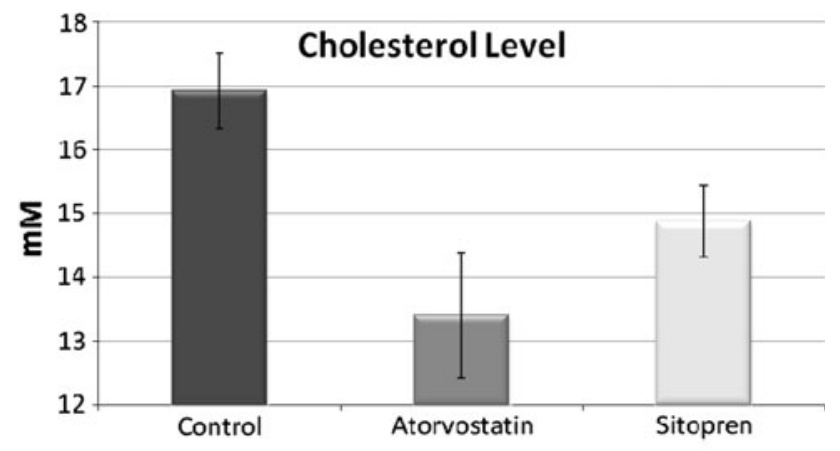

Triglyceride Level

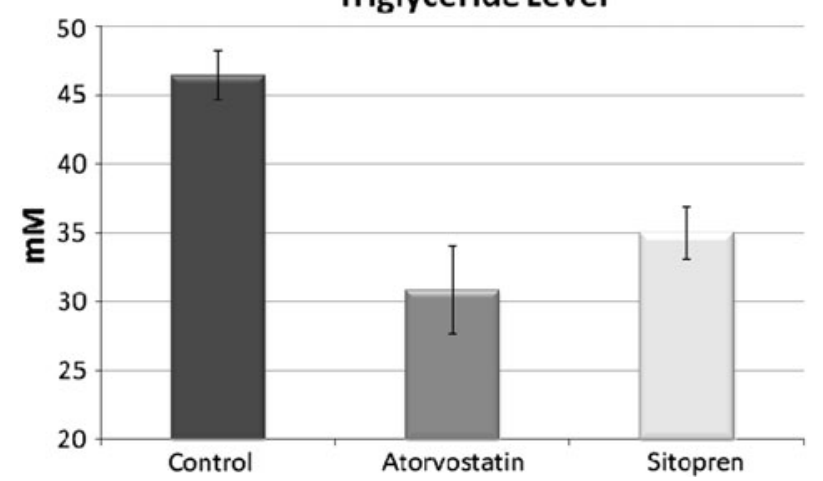

Fig. 7 Influence of $50 \mathrm{mg} /$ day $(0.4 \mathrm{mg} /$ day of sodium polyprenyl phosphate, $2.4 \mathrm{mg} /$ day of $\beta$-sitosterol) of Sitopren or $0.8 \mathrm{mg} /$ day of atorvastatin (each in $0.5 \mathrm{ml}$ of RPMI-1640, Sigma-Aldrich, intragastric administration) on cholesterol and triglyceride levels in serum of hyperlipidemic mice. Control group mice were treated by the same way with $0.5 \mathrm{ml}$ of the diluent without the active ingredient. All mice were injected intraperitoneally with poloxamer-407 $(7.5 \mathrm{mg} / \mathrm{mouse}$, every other day, four times) to cause pronounced hyperlipidemia; both control and experimental group contained $\geq 10$ animals. Shown are mean values $\pm \mathrm{SD} ; p<0.05$

could be explained by manifestation of its anti-inflammatory and immunomodulatory action. It should be noted that the daily doses of $\beta$-sitosterol and polyprenyl phosphate as a constituents of Sitopren (Narovlyansky et al. 2011) were proved to be substantially lower than that of cited in literature for phytosterols (Marangoni and Poli 2010) or PreOH (Roschin and Soultanov 2003; Soultanov et al. 2010) per se for appreciable lowering of cholesterol level in men. The reason of the phenomenon is still not understood and needs further investigation.

These findings form a basis for performing a detailed study of Sitopren action upon the main pathogenetic mechanisms of initiation and development of atherosclerosis such as vascular inflammation and hypercholesterolemia.

\section{Conclusions}

1. Plants are accessible renewable source of a great number of physiologically active substances which are important for human health.
2. Plant polyisoprenoids (PreOH and polyprenyl phosphates) are able to diminish the levels of blood cholesterol affecting its biosynthetic pathway. They also prevent toxic injuries of the liver and restore disturbed hepatic functions. At the same time polyprenyl phosphates express anti-inflammatory activity suppressing lipoxygenase activity and lowering the levels of proinflammatory cytokines.

3. Plant sterols (phytosterols) are natural inhibitors of cholesterol absorption from intestine.

4. Plant polyisoprenoids and phytosterols are non-toxic substances and have practically no negative side effects.

5. These compounds were found to be useful in the course of prevention and treatment of hypercholesterolemia taken separately, or in combination with chemotherapeutic preparations.

6. Combined use of polyprenyl phosphate and $\beta$-sitosterol leads to substantial enhancement of the ability to facilitate the initiation and the progress of hypercholesterolemia in comparison with such for phytosterols or PreOH per se. This phenomenon is very valuable for the development of the new type of anti-hyperlipidemic BAFS and preparations consisting exclusively of natural substances like Sitopren.

Open Access This article is distributed under the terms of the Creative Commons Attribution License which permits any use, distribution, and reproduction in any medium, provided the original author(s) and the source are credited.

\section{References}

Beltowski G, Wojcicka G, Jamroz-Wisniewska A (2009) Adverse effects of statins-mechanism and consequences. Curr Drug Saf 4:209-228

Bergamini E, Bizzarri R, Cavallini G et al (2004) Ageing and oxidative stress: a role of dolichol in the antioxidant machinery of cell membranes. J Alzheimers Dis 6:129-135

Binghorst M, Wortmann SB, Funke S et al (2012) Glycosylation defects underlying fetal alcohol spectrum disorder: a novel pathogenetic model. J Inherit Metab Dis 35:399-405

Blanc M, Hsieh WY, Robertson KA et al (2011) Host defense against viral infection involves interferon mediated down-regulation of sterol biosynthesis. PLoS Biol 9:e1000598

Bonnans C, Levy BD (2007) Lipid mediators as agonists for the resolution of acute lung inflammation and injury. Am J Respir Cell Mol Biol 36:201-205

Buhaescu I, Izzedine H (2007) Mevalonate pathway: a review of clinical and therapeutical implications. Clin Biochem 40:575-584

Cantagrel V, Lefeber DJ (2011) From glycosylation disorders to dolichol biosynthesis defects: a new class of metabolic diseases. J Inherit Metab Dis 34:859-867

Cantagrel V, Lefeber DJ, Ng BG et al (2010) SRD5A3 is required for conversion of polyprenol to dolichol and is mutated in a congenital glycosylation disorder. Cell 142:203-217

Chojnacki T, Dallner E (1988) The biological role of dolichol. Biochem J 251:1-9 
Clase AC, Lyman MG, del Rio T et al (2003) The pseudorabies virus Us2 protein, a virion tegument component, is prenylated in infected cells. J Virol 77:12285-12298

Danilov LL, Maltsev SD, Deyeva AV et al (1996) Phosprenyl: a novel drug with antiviral and immunomodulatory activity. Arch Immunol Ther Exp 44:395-400

Danilov LL, Deyeva AV, Mal'tsev SD et al (1999) Composition for prophylaxis and treatment of infections and for correction of pathological states of living organism. Patent RU 2129867

Danilov LL, Deeva AV, Kuritz T et al (2003) Therapeutic composition and methods. Patent US 6525035

Einav S, Glenn JS (2003) Prenylation inhibitors: a novel class of antiviral agents. J Antimicrob Chemother 52:883-886

Fernandez ML, Vega-Lopez S (2005) Efficacy and safety of sitosterol in the management of blood cholesterol levels. Cardiovasc Drug Rev 23:57-70

Goreta SS, Dabelic S, Dumic J (2012) Insight into complexity of congenital disorders of glycosylation. Biochem Med 22:156-170

Grundahl JEH, Guan Z, Rust S et al (2012) Life with too much polyprenol: polyprenol reductase deficiency. Mol Genet Metab 105:642-651

Gupta AK, Savapoulos CG, Ahuja G et al (2011) Role of phytosterols in lipid-lowering: current perspectives. QJM 104:301-308

Hartley MD, Imperiali B (2012) At the membrane frontier: a prospectus on the remarkable evolutionary conservation of polyprenols and polyprenyl phosphates. Arch Biochem Biophys 517:83-97

Ishimoto K, Tachibana K, Hanano I et al (2010) Sterol-regulatoryelement-binding protein 2 and nuclear factor Y control human farnesyl diphosphate synthase expression and affect cell proliferation in hepatoblastoma cells. Biochem J 429:347-357

IUPAC-IUB Joint Commission on Biochemical Nomenclature (JCBN) (1987) Prenol nomenclature recommendations. Eur J Biochem 167:181-184

Johnston TP (2004) The P-407-induced murine model of dosecontrolled hyperlipidemia and atherosclerosis: a review of findings to date. J Cardiovasc Pharmacol 43:595-606

Jones MB, Rosenberg JN, Betenbaugh MJ et al (2009) Structure and synthesis of polyisoprenoids used in $\mathrm{N}$-glycosylation across the three domains of life. Biochim Biophys Acta 1790:485-494

Kapadia SB, Chisari FV (2005) Hepatitis C virus RNA replication is regulated by host geranylgeranylation and fatty acids. Proc Natl Acad Sci USA 102:2561-2566

Kozlov VV, Danilov LL (2012) Separation of polyprenyl phosphate oligomerhomologues by reversed-phase ion-pair high-performance liquid chromatography. Analyt Sci 28:1021-1023

Kranz C, Ungeblut C, Denecke J et al (2007) A defect in dolichol phosphate biosynthesis causes a new inherited disorder with death in early infancy. Am J Hum Gen 80:433-440

Kuritz T (2009) Methods and compositions for modulation of innate immunity. Patent US 0306017

Larkin A, Imperiali B (2011) The expanding horizons of asparagineslinked glycosylation. Biochemistry 50:4411-4426

Marangoni S, Poli A (2010) Phytosterols and cardiovascular health. Pharmacol Res 61:193-199

Marquart TJ, Allen RM, Ory DS et al (2010) miR-33 links SREBP-2 induction to repression of sterol transporters. Proc Natl Acad Sci USA 107:12228-12232

Narovlyansky AN, Pronin AV, Sanin AV et al (2011) Biologically active additive and method for its production. Patent RU 2427284

Nebieridze DV, Chernova SI (2012) The investigation of efficiency and safety on administering combination of polyprenyl phosphate with beta-sitosterol in patients with disturbance of lipid metabolism (in Russian). Profilakticheskaya Medicina
Ozherelkov SV, Timofeyev AV, Novikova GP et al (2000) Protective action of novel antiviral preparation phosprenyl at experimental tick-borne encephalitis (in Russian). Vopr Virusol 45:33-37

Ozherelkov SV, Kupriyanov VV, Kalinina ES et al (2007) Interferonogenic activity of tick-borne encephalitis virus and polyprenylcontaining compounds in sensitive cell cultures (in Russian). In: Interferon-50 let [50th Anniversary of the Interferon], Proceedings of the Conference, 19-20 November, Moscow, pp 184-191

Pronin AV, Ozherelkov SV, Deyeva AV et al (2012) Polyprenyl phosphates as adjuvants polarizing immune response in the direction of Th1 (in Russian). Infektsiya Immunitet 3:645-650

Rauthan M, Pilon M (2011) The mevalonate pathway in C. elegans. Lipids Health Dis 10:243-254

Roschin VI, Soultanov VS (2003) Preparation for stimulation of natural regeneration of liver. Patent RU 2252026

Rozner S, Garti N (2006) The activity and absorption relationship of cholesterol and phytosterols. Colloids Surf A 282-283:435-456

Sanin AV, Ganshina IV, Sud'ina GF et al (2011) Phosphorylated polyprenols - a novel class of compounds with anti-inflammatory and broncholytic activity (in Russian). Infektsiya Immunitet $1: 355-360$

Sasaki J, Otonari T, Sawayama Y et al (2011) Double-dose pravastatin versus add-on ezetimibe with low-dose pravastatin-effects on LDL cholesterol, cholesterol absorption, and cholesterol synthesis in Japanese patients with hypercholesterolemia (PEAS study). J Atheroscler Thromb 18:1-9

Sato R (2010) Sterol metabolism and SREBP activation. Arch Biochem Biophys 501:177-181

Schenk B, Fernandez F, Waechter CJ (2001) The ins(ide) and outs(ide) of dolichyl phosphate biosynthesis and recycling in the endoplasmic reticulum. Glycobiology 11:61R-70R

Singh G, Gupta P, Rawat P (2007) Antidyslipidemic activity of polyprenol from Coccinia grandis in high-fat diet-fed hamster model. Phytomedicine 14:792-798

Skorupinska-Tudek K, Wojcik J, Swiezewska E (2008) Polyisoprenoid alcohols-recent results of structural studies. Chem Rec 8:33-45

Soultanov VS, Agishev VG, Monahova IA et al (2010) Ropren improves liver and pancreatic functions in patients with chronic alcoholism. Gastroenterologia Sankt-Peterburga 4:12-17

Surmacz L, Swiezewska E (2011) Polyisoprenoids-secondary metabolites or physiologically important superlipids? Biochem Biophys Res Comm 407:627-632

Swiezewska E, Danikiewicz W (2005) Polyisoprenoids: structure, biosynthesis and function. Progr Lipid Res 44:235-258

Tamilselvan N, Thirumalai T, Elumalai EK et al (2011) Pharmacognosy of Coccinia grandis: a review. Asian Pac J Trop Biomed 211:S299-S302

Tremblay AJ, Lamarche B, Lemelin V et al (2011) Atorvastatin increases intestinal expression of NPLC1L1 in hyperlipidemic men. J Lipid Res 52:558-565

Vasil'ev AN, Ozherelkov SV, Kozlov VV et al (2008) Antiviral and immunomodulatory activity of polyprenyl phosphates at viral infections (in Russian). Antibiotiki Khimioterapiya 53:3-8

Wang X, Mansourian AR, Quinn PJ (2008) The effect of dolichol on structure and phase behavior of phospholipid model membranes. Mol Membr Biol 25:547-556

Yamatsu I, Suzuki T, Abe S et al (1986) Therapeutic and preventive agent containing dolichol. Patent US 4613593

Yang L, Wang CZ, Ye JZ et al (2011) Hepatoprotective effects of polyprenols from $G$. biloba $\mathrm{L}$. leaves on $\mathrm{CCl}_{4}$-induced hepatotoxicity in rats. Fitoterapia 82:834-840

Yu J, Wang Y, Qian H et al (2012) Polyprenols from Taxus chinensis var. mairei prevent the development of $\mathrm{CCl}_{4}$-induced liver fibrosis in rats. J Ethnopharmacol 142:151-160 